\title{
Trace element profile and incidence of type 2 diabetes, cardiovascular disease and colorectal cancer: results from the EPIC-Potsdam cohort study
}

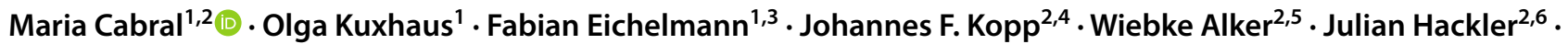 \\ Anna P. Kipp ${ }^{2,7} \cdot$ Tanja Schwerdtle ${ }^{2,4} \cdot$ Hajo Haase ${ }^{2,5} \cdot$ Lutz Schomburg $^{2,6} \cdot$ Matthias B. Schulze $^{1,2,3,4,8}$
}

Received: 3 August 2020 / Accepted: 13 January 2021 / Published online: 15 February 2021

(C) The Author(s) 2021

\begin{abstract}
Purpose We aimed to examine the prospective association between manganese, iron, copper, zinc, iodine, selenium, selenoprotein $\mathrm{P}$, free zinc, and their interplay, with incident type 2 diabetes (T2D), cardiovascular disease (CVD) and colorectal cancer (CRC).

Methods Serum trace element (TE) concentrations were measured in a case-cohort study embedded within the EPIC-Potsdam cohort, consisting of a random sub-cohort $(n=2500)$ and incident cases of T2D $(n=705)$, CVD $(n=414)$, and CRC $(n=219)$. TE patterns were investigated using principal component analysis. Cox proportional hazard models were fitted to examine the association between TEs with T2D, CVD and CRC incidence.

Results Higher manganese, zinc, iodine and selenium were associated with an increased risk of developing T2D (HR Q5 vs Q1: 1.56, 1.09-2.22; HR per SD, 95\% CI 1.18, 1.05-1.33; 1.09, 1.01-1.17; 1.19, 1.06-1.34, respectively). Regarding CVD, manganese, copper and copper-to-zinc ratio were associated with an increased risk (HR per SD, 95\% CI 1.13, 1.00-1.29; $1.22,1.02-1.44 ; 1.18,1.02-1.37$, respectively). The opposite was observed for higher selenium-to-copper ratio (HR Q5 vs Q1, 95\% CI 0.60, 0.39-0.93). Higher copper and zinc were associated with increasing risk of developing CRC (HR per SD, 95\% CI 1.29, 1.05-1.59 and 1.14, 1.00-1.30, respectively). Selenium, selenoprotein P and selenium-to-copper-ratio were associated to decreased risk (HR per SD, 95\% CI 0.82, 0.69-0.98; 0.81, 0.72-0.93; 0.77, 0.65-0.92, respectively). Two TE patterns were identified: manganese-iron-zinc and copper-iodine-selenium.

Conclusion Different TEs were associated with the risk of developing T2D, CVD and CRC. The contrasting associations found for selenium with T2D and CRC point towards differential disease-related pathways.
\end{abstract}

Keywords Trace elements $\cdot$ Prospective study $\cdot$ Type 2 diabetes mellitus $\cdot$ Cardiovascular disease $\cdot$ Colorectal cancer

Maria Cabral

maria.cabral@dife.de

1 Department of Molecular Epidemiology, German Institute of Human Nutrition Potsdam Rehbruecke, 14558 Nuthetal, Germany

2 TraceAge-DFG Research Unit on Interactions of Essential Trace Elements in Healthy and Diseased Elderly, Potsdam-Berlin-Jena, Germany

3 German Center for Diabetes Research (DZD), München-Neuherberg, Germany

4 Department of Food Chemistry, Institute of Nutritional Science, University of Potsdam, 14558 Nuthetal, Germany
5 Department of Food Chemistry and Toxicology, Institute of Food Technology and Food Chemistry, Technische Universität Berlin, 13355 Berlin, Germany

6 Institute for Experimental Endocrinology, Charité-Universitätsmedizin Berlin, corporate member of Freie Universität Berlin, Humboldt-Universität Zu Berlin, and Berlin Institute of Health, CVK, Augustenburger Platz 1, 13353 Berlin, Germany

7 Department of Molecular Nutritional Physiology, Institute of Nutritional Sciences, Friedrich Schiller University Jena, 07743 Jena, Germany

8 Institute of Nutritional Science, University of Potsdam, 14558 Nuthetal, Germany 


\section{Introduction}

Trace elements (TEs) exert a variety of cellular key functions, although they account for a very small fraction of the total body weight. TEs mediate vital biochemical reactions by acting as cofactors or catalyst for many enzymes and act as centers for stabilizing structures of enzymes and proteins. Consequently, imbalance in TE metabolism and homeostasis (deficiency or excess) may play an important role in a variety of diseases [1].

Although previous literature has suggested a link between different TEs and major age-related chronic diseases, such as type 2 diabetes (T2D), cardiovascular disease (CVD) and cancer, there appears to be substantial heterogeneity of findings from observational studies and trials. Selenium (Se) intake, for example, has been postulated to be protective for cancer development. Overall, case-control and prospective cohort studies suggest an inverse association of Se with cancer risk [2, 3], but randomized controlled trials (RCTs) do not fully support this notion. Meta-analyzing all RCTs on Se supplementation and cancer, intervention groups had no statistically different risk than control groups [4]. In case of manganese (Mn), supplementation has been shown to increase insulin secretion to improve glucose tolerance under conditions of dietary stress in animal models [5]. In humans, a recent case-control study suggested a U-shaped association of plasma Mn levels and diabetes with both low and high levels indicating higher diabetes risk [6].

The discrepancy between observational studies and intervention trials may be explainable by confounding bias in the former. Also, trial results may have been inconclusive due to low power to observe moderate effects and the inclusion of individuals with sufficient TE status. More strikingly, neither prospective observational studies nor randomized trials seem to have considered several TEs at the same time.

Attention has been recently directed to the importance of considering co-exposure of several toxicants in epidemiological studies [7-9], as failure to capture potential interactive effects of exposure may prevent the understanding of the etiopathogenic mechanisms related to many nutritional disorders [10]. However, the interplay between TEs has been sparsely characterized, thereby beneficial or detrimental effects in observational studies may also reflect effects of other correlated TEs or their interaction. For example, serum concentrations of copper $(\mathrm{Cu})$ are strictly regulated by compensatory mechanisms that insure its concentration within certain ranges of nutritional intake. This changes under inflammatory conditions where specific mechanisms decrease serum concentration of zinc $(\mathrm{Zn})$ and increase serum concentration of $\mathrm{Cu}$ [11]. Hence, a common feature of several age-related chronic diseases appears to be an increase of the $\mathrm{Cu}$-to- $\mathrm{Zn}$ ratio [11].
Based on these considerations, we aimed to investigate the prospective association of selected TEs $[\mathrm{Mn}$, iron $(\mathrm{Fe})$, $\mathrm{Cu}, \mathrm{Zn}$, iodine (I), Se] and functional TE markers [Selenoprotein $\mathrm{P}$ (SELENOP) and Free Zinc (Free $\mathrm{Zn}$ )], as well as their interdependence, with incident T2D, CVD [myocardial infarction (MI) and stroke] and colorectal cancer (CRC) using data from the European Prospective Investigation into Cancer and Nutrition (EPIC)-Potsdam cohort.

\section{Methods}

\section{Study design and population}

The EPIC-Potsdam cohort is part of the multicenter EPIC study [12]. In Potsdam and the surrounding area, 27,548 persons were recruited from the general population $(16,644$ women and 10,904 men) between 1994 and 1998, with an age range of 35-64 years [13]. The baseline examination included anthropometric measurements, a validated semiquantitative food frequency questionnaire (FFQ) [14], a lifestyle questionnaire, and a personal interview. Written informed consent was obtained from all study participants a priori, and the study was approved by the ethics committee of the Medical Society of the State of Brandenburg [13]. In course of active follow-up, participants were contacted every 2 years, with response rates ranging between 90 and $96 \%$ per follow-up round [15]. The association between TE profile and incident chronic disease was evaluated using a case-cohort design [16] with blood samples from a random sub-cohort of EPIC-Potsdam participants $(n=2500)$ and incident cases of T2D, CVD and CRC. Individuals were excluded from the analyses if they had insufficient or no serum; unclear disease status; prevalent T2D, cancer, MI, or stroke at baseline, or incomplete follow-up information (Supplementary Fig. 1). The analytic samples comprised 2741 participants for T2D (2090 sub-cohort participants and 705 incident T2D cases, overlap: 54), 2464 participants for CVD (2087 sub-cohort participants and 414 incident CVD cases, overlap: 37), and 2309 participants for CRC (2106 sub-cohort participants and 219 incident CRC cases, overlap: 16). Follow-up extended until August 2005 for T2D (median, interquartile range: of 6.6, 2.7 years); November 2006 for CVD (8.3, 1.6 years), and December 2009 for CRC $(10.7,1.6$ years).

\section{Blood collection and laboratory analysis}

At baseline, trained study personnel obtained $30 \mathrm{~mL}$ peripheral venous blood from each participant. Blood was separated into serum, plasma (with $10 \%$ of total volume citrate) and blood cells and was subsequently stored in tanks of liquid nitrogen at $-196{ }^{\circ} \mathrm{C}$ or in deep freezers 
at $-80{ }^{\circ} \mathrm{C}$ until time of analysis. For TE-profiling, the method published by Kopp et al. [17] was employed [18]. In brief, $50 \mu \mathrm{L}$ of serum sample was diluted with $440 \mu \mathrm{L}$ of a diluent solution as described in [17]. As internal standard and for isotope dilution analysis $10 \mu \mathrm{L}$ of a solution containing $50 \mu \mathrm{g} / \mathrm{L}{ }^{77} \mathrm{Se}$ and $5 \mu \mathrm{g} / \mathrm{L} \mathrm{Rh}$ was added to give a total volume of $500 \mu \mathrm{L}$. This solution was directly subjected to analysis via inductively coupled plasma tandem mass spectrometry (ICP-MS/MS) (Agilent ICP-QQQMS 8800, Agilent Technologies, Waldbronn, Germany). For external calibration (all elements except Se), standards were prepared matrix-matched in the diluent solution. Se was determined using isotope dilution analysis. For quality control, reference material RECIPE ${ }^{\circledR}$ ClinChek $^{\circledR}$ serum control lyophilized (Ref. 8880-8882, Lot 347 or Lot 1497 , each in both levels) was measured in triplicate daily. Mean recoveries were Mn: $98.5 \pm 11.1 \%$, Fe: $100.2 \pm 7.0 \%$, Cu: $95.5 \pm 6.8 \%, \mathrm{Zn}: 96.9 \pm 6.1 \%$, I: $105.9 \pm 16.4 \%$, Se: $97.3 \pm 7.9 \%$. Furthermore, sufficient blank samples (distilled $\mathrm{H} 2 \mathrm{O}$ ) were carried along to determine limits of detection (LOD, 36-criterion) and quantification (LOQ, $10 \sigma$-criterion) on a daily basis. SELENOP concentrations were measured using a validated sandwich ELISA (selenOtest ELISA, selenOmed GmbH, Berlin, Germany) characterized recently in detail [19], which was independently proven as a highly reliable commercial assay [20]. Free $\mathrm{Zn}$ concentration was determined by the low-molecularweight fluorescent probe Zinypr-1 as reported before [21], with the following modifications: The incubation times for $F, F_{\min }$ and $F_{\max }$ were set to 30,20 and $30 \mathrm{~min}$, respectively. For the induction of $F_{\min } 15 \mu \mathrm{L}$ EDTA-solution (stock $800 \mu \mathrm{M}$, final concentration $104 \mu \mathrm{M}$ ) and for $F_{\text {max }}$ $15 \mu \mathrm{L} \mathrm{ZnSO}_{4}$-solution (stock $4.5 \mathrm{mM}$; final concentration $0.52 \mathrm{mM}$ ) were added per well. Plasma concentrations of high-density lipoprotein cholesterol (HDL-C) and high-sensitivity CRP (hsCRP), as well as the percentage of glycated hemoglobin (HbA1c) were measured at the Department of Internal Medicine, University of Tübingen (Tübingen, Germany) with an automatic ADVIA 1650 analyzer (Siemens Medical Solutions, Erlangen, Germany) in 2007 [22]. All biomarker measurements conducted in plasma were corrected for the dilution introduced by citrate volume to improve comparability with concentrations measured in EDTA-plasma reported in the literature [23]. Because some incident CRC cases had these biomarkers measured at a later stage, potential differences in the old and new measurements were evaluated in a subsample of 31 cases and 30 controls with repeated measurements. The values were corrected using the median of the differences in old and new values $(-0.12 \%$ for $\mathrm{HbA} 1 \mathrm{c}$, $-0.023 \mathrm{mg} / \mathrm{L}$ for hsCRP and $5.74 \mathrm{mg} / \mathrm{dL}$ for HDL-C, respectively). Laboratory measurements were conducted by experienced technical personnel following the manufacturer's instructions.

\section{Outcome ascertainment}

Incident cases of diabetes were identified during follow-up via self-reports of a diabetes diagnosis, diabetes-relevant medication, or dietary treatment due to diabetes. All incident cases were verified by questionnaires mailed to the diagnosing physician asking about the date and type of diagnosis, diagnostic tests, and treatment of diabetes. Only cases with a physician diagnosis of T2D, classified according to the International Statistical Classification of Diseases, 10th Revision (ICD10: E11) and a diagnosis date after the baseline examination were considered as confirmed incident cases of T2D. Incident MI and stroke cases were identified by self-report in follow-up questionnaires or by death certificate. To increase sensitivity, the questionnaire included additional questions about typical stroke symptoms [12, 24]. All self-reports for CVD cases were verified by contacting the patients' treating physicians or by review of death certificates according to World Health Organization Monitoring of Trends and Determinants in Cardiovascular Disease criteria [25]. Cases were classified as incident MI (ICD-10 I21), ischemic stroke (IS) (ICD-10 I63.0 to I63.9), hemorrhagic stroke (ICD-10 I60.0 to I61.9), or undetermined stroke (ICD-10 I64.0 to I64.9) by two physicians in the study center [26]. Only confirmed cases were considered for analysis. CVD cases were calculated by combining the verified incident cases of MI and stroke depending on whichever occurred first. Accordingly, to verify cancer status, once a participant was identified as a potential case, a standard inquiry form was sent to the treating physician and then evaluated by study physicians. CRC incident cases comprised diagnoses of carcinomas of the proximal colon (codes C18.0-18.5), distal colon (codes C18.6 and C18.7), and rectum (codes C19 and C20). Followup was defined as the time between enrollment and study exit, which was determined by diagnosis of the respective disease, death, dropout, or the censoring date, whichever occurred first.

\section{Baseline anthropometry and lifestyle characteristics}

Baseline measurement of anthropometric parameters was obtained by trained personnel with the participants dressed in light clothes and barefoot. BMI was calculated as the ratio of body weight $(\mathrm{kg})$ to height squared $\left(\mathrm{m}^{2}\right)$. Waist circumference was measured midway between the lower rib margin and the superior anterior iliac spine to the nearest $0.5 \mathrm{~cm}$ with a non-stretching tape applied horizontally.

Measurements of systolic and diastolic blood pressure (BP) were obtained after a resting period of 15-30 min [27]. History of hypertension was defined as systolic 
$\mathrm{BP} \geq 140 \mathrm{mmHg}$, diastolic $\mathrm{BP} \geq 90 \mathrm{mmHg}$, self-reported hypertension diagnosis, or use of antihypertensive medication.

Information on educational attainment, smoking, medication and leisure time physical activity was assessed with a self-administered questionnaire and a personal interview by trained interviewers using a computer-assisted interview [12]. We considered sport activities, cycling and gardening as leisure time activities, calculated as the average time spent per week during the 12 months before the baseline recruitment.

A food frequency questionnaire (FFQ) measuring usual diet over the past 12 months was administered to the participants to collect information on amount and frequency of food and beverage intake, at baseline [14, 28]. Information regarding supplement use was also collected from this FFQ. In particular, participants were asked whether they were regularly (continuously for at least 4 weeks) taking the following preparations: mineral tablets (yes/no), vitamin tablets (yes/no). A diet score (referring to the Mediterranean diet score adapted to non-Mediterranean populations) was computed at baseline to study overall healthy diet as a determinant of TE status. Construction of this score has been fully described elsewhere [29].

\section{Statistical analysis}

\section{Descriptive statistics}

General demographic and laboratory characteristics were summarized as mean \pm standard deviation (SD) or as median with interquartile range (IQR), depending on the normality of the continuous variables. Categorical variables were summarized as proportions.

\section{Treatment of left-censored and missing data}

For Mn, 483 concentration values were below the LOD, and 364 concentration values were below the LOQ. Leftcensored data were handled by substituting by LOD $/ \sqrt{ } 2$ for censored values less than LOD and by LOQ $/ \sqrt{ } 2$ for censored values less than LOQ. Missing values ( $\sim 10 \%$ of the total sample) were handled using multiple imputation based on the fully conditional specification method [30]. SAS PROC MIANALYZE ${ }^{\circledR}$ was used to combine the results of the analyses on 5 imputed datasets and to generate valid statistical inferences.

\section{Assessment of TE markers interdependence}

The relationship between TE markers was investigated through age and sex-adjusted Spearman's correlation coefficients in the full sample $(n=3834)$, followed by principal component analysis (PCA). Briefly, PCA is a major dimension reduction technique that aggregates variables on the basis of the degree to which they are correlated with one another. The goal is to identify linear composites of optimally weighted variables (principal components) that account for the largest amount of variation in TEs between participants. The factors were orthogonally rotated with the 'VARIMAX option', using the PROC FACTOR ${ }^{\circledR}$ procedure in SAS. The number of factors retained was based on eigenvalue $>1$, a scree-test and the interpretability of factors.

\section{TE profile and risk of type 2 diabetes, cardiovascular disease and colorectal cancer}

We used Cox proportional hazards regression models to estimate multivariable-adjusted hazard ratios (HRs) and 95\% confidence intervals (CIs) for the associations of TEs with each incident chronic disease (T2D, CVD and CRC). Possible nonlinear relationships were further examined with restricted cubic splines, with three knots fitted at the 10th, 50th and 90th percentile of TE distribution, and the cubic spline and linear models were compared using likelihood ratio test. The associations were estimated modelling individual TEs as well as identified TE patterns continuously for which a logarithmic transformation and a Z-standardization (mean $=0, \mathrm{SD}=1$ ) were used to improve normality and comparability, and categorically (according to quintiles of TE distribution in the subcohort) for the associations that deviated from linearity. To account for the case-cohort study design, weights were assigned using the approach proposed by Prentice [16, 31], and robust variance estimators were used to calculate $95 \%$ CIs using the methods described by Lin and Wei [32]. We assessed Schoenfeld residuals to validate the appropriateness of the proportional hazard's assumption. We defined the dependent time variable as the time period between age of recruitment and the age of exit (age of diagnoses or age of death or censoring). To be less sensitive to violations of the HR, the models were stratified by age in years. Sex, education (no degree/vocational training, trade/technical school, university degree), BMI, waist circumference, smoking status (never smokers, ex-smokers, current smokers), overall leisure-time physical activity (defined as the sum of sports, biking and gardening in $\mathrm{h} /$ week), alcohol consumption categories according to recommended upper limits $(0 \mathrm{~g},<=12 \mathrm{~g}$ for women $/<=24 \mathrm{~g}$ for men, $>12 \mathrm{~g}$ for women/> $24 \mathrm{~g}$ for men), prevalent hypertension (yes or no), anti-hypertensive and lipid-lowering medication (yes or no), vitamin and mineral preparations (yes or no), and dietary quality (assessed by the Mediterranean score) were considered as covariates in the Cox models to account for potential confounding. By testing cross-product terms in the fully adjusted model, we did not detect evidence 
for effect modification by age or sex and therefore present results from pooled models.

In addition, we assessed the relationship of TEs with HbA1c, HDL-C and hsCRP through age and sex-adjusted spearman correlations, to explore possible mediating effects of metabolic markers.

In a sensitivity analysis, we repeated all the analyses excluding TEs higher than the 99th percentile.

All statistical analyses were performed using the statistical software package SAS (version 9.4, Enterprise Guide 7.1, SAS Institute Inc., Cary, NC, USA), with a significance level of 0.05 for 2-sided tests.

\section{Results}

\section{Characteristics of the participants}

Baseline characteristics of the subcohort according to median concentrations of TEs are presented in Table 1. No major differences were observed regarding TE concentrations and the observed characteristics, with the exception of $\mathrm{Cu}$. Participants with higher $\mathrm{Cu}$ concentrations were more likely to be women, have lower educational attainment and lower alcohol consumption.

\section{Interdependence of serum TE and other biomarkers}

Age and sex-adjusted Spearman's correlation coefficients between TEs and potential mediators are shown in Table 2.

Correlations between TEs and functional biomarkers (SELENOP and Free-Zn) were low to modest and ranged from -0.06 to 0.45 . The strongest correlation was observed between Se and SELENOP $(r=0.45)$, followed by $\mathrm{Cu}$ and I $(r=0.43)$ and $\mathrm{Zn}$ and Free-Zn (0.33). Cu and hsCRP were moderately correlated $(r=0.43)$.

We identified two patterns of TEs by PCA that accounted for $43 \%$ of the total variance. The first pattern was mainly related to higher concentrations of $\mathrm{Mn}, \mathrm{Fe}$ and $\mathrm{Zn}$ and the second pattern to higher concentrations of $\mathrm{Cu}, \mathrm{I}$ and $\mathrm{Se}$ (Fig. 1).

\section{TEs and risk of type 2 diabetes}

In the spline regression analysis, the shape of the observed associations of $\mathrm{Fe}, \mathrm{Cu}, \mathrm{Zn}$, Se, SELENOP, Free $\mathrm{Zn}, \mathrm{Cu}-$ to- $\mathrm{Zn}$ ratio and $\mathrm{Se}-$ to- $\mathrm{Cu}$ ratio with $\mathrm{T} 2 \mathrm{D}$ was linear, while associations of $\mathrm{Mn}$, and factor 2 deviated from linearity (Supplementary Fig. 2).

After adjustments for age, sex, education and established T2D risk factors, higher concentrations of $\mathrm{Mn}, \mathrm{Zn}, \mathrm{I}, \mathrm{Se}$, and SELENOP were associated with a higher risk of developing T2D (HR Q5 vs Q1, 95\% CI 1.54, 1.10-2.17 for Mn; HR per SD, 95\% CI 1.24, 1.12-1.38 for $\mathrm{Zn}$; $1.11,1.03-1.20$ for I; $1.26,1.12-1.41$ for Se; $1.14,1.02-1.29$ for SELENOP) (Fig. 2). In the final model, in which further adjustment was made for the respective other main TEs, higher concentrations of $\mathrm{Mn}, \mathrm{Zn}, \mathrm{I}$ and Se did not markedly change in their association with diabetes risk (HR Q5 vs Q1: 1.56, 1.09-2.22 for Mn; HR per SD, 95\% CI 1.18, 1.05-1.33 for $\mathrm{Zn}$; 1.09, 1.01-1.17 for I; 1.19, 1.06-1.34 for Se), while SELENOP was largely attenuated (HR per SD, 95\% CI 1.04, 0.92-1.18). No association was observed for Fe, Free Zn, $\mathrm{Cu}$-to-Zn ratio and Se-to-Cu ratio (Supplementary Table 1).

Regarding the TE patterns, in the multi-variable adjusted models, both Factor $1(\mathrm{Mn}-\mathrm{Fe}-\mathrm{Zn})$ and Factor $2(\mathrm{Cu}-\mathrm{I}-\mathrm{Se})$ were positively associated with the risk of developing T2D (HR per SD, 95\% CI 1.19, 1.09-1.30 for Factor 1; HR Q5 vs Q1, 95\% CI 1.76, 1.21-2.56 for Factor 2). We next conducted a stepwise approach adjusting pattern associations one by one for different TEs. Adjustment for $\mathrm{Zn}$ attenuated the relationship between the pattern 1 and the risk of T2D (HR per SD, 95\% CI 1.11, 1.00-1.24). For factor 2, the adjustment for $\mathrm{Zn}$ and Se had the strongest impact on the association between the pattern and T2D (HR Q5 vs Q1, 95\% CI 1.47, 0.98-2.18 with adjustment for $\mathrm{Zn}$ and 1.02, 0.54-1.94 with adjustment for Se) (Table 3).

\section{TEs and risk of cardiovascular disease}

In the spline regression analysis, the shape of the observed associations of each TE, the functional markers, Se-to- $\mathrm{Cu}$ ratio and both TE patterns with CVD was linear, while the association for the Se-to-Cu ratio deviated from linearity (Supplementary Fig. 3).

After adjustments for age, sex, education and established risk factors, higher concentrations of $\mathrm{Mn}, \mathrm{Cu}, \mathrm{I}$ and $\mathrm{Cu}$-to$\mathrm{Zn}$ ratio were associated with a higher risk of developing CVD (HR per SD, 95\% CI 1.15, 1.02-1.30 for Mn; 1.31, 1.13-1.52 for $\mathrm{Cu} ; 1.26,1.09-1.45$ for $\mathrm{I} ; 1.18,1.02-1.37$ for $\mathrm{Cu}$-to- $\mathrm{Zn}$ ratio), whereas, $\mathrm{Se}$-to- $\mathrm{Cu}$ ratio was inversely associated with CVD incidence (HR Q5 vs Q1, 95\% CI 0.60, 0.39-0.93) (Fig. 2). In the final model, in which further adjustment was made for the respective other main TEs ( $\mathrm{Mn}, \mathrm{Fe}, \mathrm{Cu}, \mathrm{Zn}, \mathrm{I}$ and $\mathrm{Se}$ ), the associations observed for $\mathrm{Mn}$ and $\mathrm{Cu}$ were slightly attenuated (HR per SD, 95\% CI $1.13,1.00-1.29$ for $\mathrm{Mn}$ and 1.22, 1.02-1.44 for $\mathrm{Cu}$ ), while for I the association strongly attenuated (HR per SD, 95\% CI 1.17, 0.99-1.38). No significant associations were observed for Fe, Zn, Se and SELENOP (Supplementary Table 2).

With regard to the TE patterns, no significant association was observed for factor 1 , while factor 2 presented a positive association with CVD risk after adjustment for age, sex, education and established CVD risk factors (HR per SD, 95\% CI 1.17, 1.02-1.35). After conducting a stepwise approach adding one by one the different TEs to the 
Table 1 Baseline characteristics of the EPIC-Potsdam subcohort according to median concentrations of trace elements, imputed sample, $n=2087$

\begin{tabular}{|c|c|c|c|c|c|c|c|c|}
\hline & \multirow{2}{*}{\multicolumn{2}{|c|}{$\begin{array}{l}\text { Manganese }(\mu \mathrm{g} / \mathrm{L}) \\
\text { Median }(\mathrm{IQR}): 1.04 \\
(1.14)\end{array}$}} & \multirow{2}{*}{\multicolumn{2}{|c|}{$\begin{array}{l}\text { Iron }(\mu \mathrm{g} / \mathrm{L}) \\
\text { Median (IQR): } 928 \\
(433)\end{array}$}} & \multirow{2}{*}{\multicolumn{2}{|c|}{$\begin{array}{l}\text { Copper }(\mu \mathrm{g} / \mathrm{L}) \\
\text { Median (IQR): } 1021 \\
(333)\end{array}$}} & \multirow{2}{*}{\multicolumn{2}{|c|}{$\begin{array}{l}\operatorname{Zinc}(\mu \mathrm{g} / \mathrm{L}) \\
\text { Median (IQR): } 728 \\
(185)\end{array}$}} \\
\hline & & & & & & & & \\
\hline & $<1.04$ & $\geq 1.04$ & $<928$ & $\geq 928$ & $<1021$ & $\geq 1021$ & $<728$ & $\geq 728$ \\
\hline Female (\%) & 65.2 & 59.8 & 67.2 & 57.9 & 42.1 & 82.9 & 66.4 & 58.7 \\
\hline Age $(\text { years })^{\mathrm{a}}$ & $50.5(15.5)$ & $47.9(15.6)$ & $48.8(14.4)$ & $49.0(16.4)$ & $49.0(15.0)$ & $48.7(16.1)$ & $48.5(15.2)$ & $49.8(15.8)$ \\
\hline $\operatorname{BMI}\left(\mathrm{kg} / \mathrm{m}^{2}\right)^{\mathrm{b}}$ & $25.9(4.3)$ & $25.9(3.9)$ & $25.9(4.3)$ & $25.8(3.8)$ & $25.7(3.8)$ & $26.1(4.4)$ & $25.7(4.2)$ & $26.0(4.0)$ \\
\hline Waist circumference $(\mathrm{cm})^{\mathrm{b}}$ & $84.6(12.5)$ & $85.6(12.5)$ & $84.7(12.8)$ & $85.5(12.3)$ & $87.0(12.6)$ & $83.2(12.1)$ & $84.3(12.6)$ & $85.9(12.4)$ \\
\hline University degree $(\%)$ & 38.5 & 40.6 & 38.0 & 41.0 & 46.0 & 33.1 & 39.3 & 39.8 \\
\hline Leisure-time physical activity (h/week) ${ }^{a}$ & $4.5(6.0)$ & $4.5(6.5)$ & $4.5(6.0)$ & $5.0(6.5)$ & $5.0(6.5)$ & $4.0(6.0)$ & $4.5(6.0)$ & $5.0(6.5)$ \\
\hline Use of vitamin supplement, yes (\%) & 17.8 & 15.3 & 16.8 & 16.4 & 17.5 & 15.7 & 15.9 & 17.3 \\
\hline Use of mineral preparation, yes (\%) & 12.6 & 11.3 & 12.1 & 11.8 & 10.8 & 13.1 & 10.1 & 13.7 \\
\hline Current smokers, $\%$ & 20.0 & 20.6 & 20.1 & 20.6 & 21.0 & 19.6 & 19.1 & 21.5 \\
\hline $\begin{array}{l}\text { High alcohol consumption ( }>12 \mathrm{~g} \text { for } \\
\text { women, }>24 \mathrm{~g} \text { for men) }(\%)\end{array}$ & 26.5 & 28.5 & 25.6 & 29.4 & 31.3 & 23.6 & 26.1 & 28.8 \\
\hline Prevalent hypertension (\%) & 48.9 & 42.9 & 43.4 & 48.4 & 45.1 & 46.8 & 43.6 & 48.2 \\
\hline Anti-hypertensive medication (\%) & 18.9 & 13.6 & 16.0 & 16.5 & 14.5 & 18.0 & 15.7 & 16.8 \\
\hline Lipid-lowering medication (\%) & 4.1 & 3.4 & 3.3 & 4.2 & 4.0 & 3.4 & 3.8 & 3.7 \\
\hline \multirow[t]{4}{*}{ Mediterranean score $^{\mathrm{b}}$} & $9.0(2.7)$ & $8.9(2.7)$ & $8.9(2.8)$ & $9.0(2.7)$ & $9.1(2.8)$ & $8.8(2.7)$ & $9.0(2.7)$ & $9.0(2.7)$ \\
\hline & \multicolumn{2}{|c|}{ Iodine $(\mu \mathrm{g} / \mathrm{L})$} & \multicolumn{2}{|c|}{ Selenium $(\mu \mathrm{g} / \mathrm{L})$} & \multicolumn{2}{|c|}{ Selenoprotein P (mg/L) } & \multicolumn{2}{|c|}{ Free zinc $(\mathrm{nM})$} \\
\hline & \multicolumn{2}{|c|}{$\begin{array}{l}\text { Median (IQR): } 56.7 \\
(15.9)\end{array}$} & \multicolumn{2}{|c|}{$\begin{array}{l}\text { Median (IQR): } 80.0 \\
\text { (19.1) }\end{array}$} & \multicolumn{2}{|c|}{ Median (IQR): 5.3 (1.8) } & \multicolumn{2}{|c|}{$\begin{array}{l}\text { Median (IQR): } 0.59 \\
(0.31)\end{array}$} \\
\hline & $<56.7$ & $\geq 56.7$ & $<80.0$ & $\geq 80.0$ & $<5.3$ & $\geq 5.3$ & $<0.59$ & $\geq 0.59$ \\
\hline Female (\%) & 51.5 & 73.5 & 61.7 & 63.4 & 67.4 & 57.3 & 60.3 & 64.9 \\
\hline Age $(\text { years })^{\mathrm{a}}$ & $50.4(15.0)$ & $47.9(15.7)$ & $49.4(16.2)$ & $48.5(14.9)$ & $47.8(15.5)$ & $50.7(15.0)$ & $48.9(16.0)$ & 48.8 (15.0) \\
\hline $\mathrm{BMI}\left(\mathrm{kg} / \mathrm{m}^{2}\right)^{\mathrm{b}}$ & $26.0(4.1)$ & $25.8(4.1)$ & $25.9(4.3)$ & $25.9(3.9)$ & $25.6(4.2)$ & $26.2(4.0)$ & $26.1(4.3)$ & $25.6(3.9)$ \\
\hline Waist circumference $(\mathrm{cm})^{\mathrm{b}}$ & $86.6(12.7)$ & $83.6(12.2)$ & $85.2(12.9)$ & $85.0(12.1)$ & $83.7(12.6)$ & $86.6(12.3)$ & $86.1(13.0)$ & $84.1(12.0)$ \\
\hline University degree (\%) & 42.7 & 39.4 & 38.7 & 40.4 & 37.9 & 41.3 & 38.8 & 40.3 \\
\hline Leisure-time physical activity (h/week) ${ }^{\mathrm{a}}$ & $5.0(6.5)$ & $4.0(5.5)$ & $5.0(6.5)$ & $4.5(6.0)$ & $4.5(6.0)$ & $5.0(6.5)$ & $4.5(6.0)$ & $5.0(6.3)$ \\
\hline Use of vitamin supplement, yes (\%) & 16.4 & 16.7 & 14.9 & 18.2 & 15.2 & 18.1 & 15.4 & 17.8 \\
\hline Use of mineral preparation, yes (\%) & 11.4 & 12.5 & 11.3 & 12.6 & 10.8 & 13.1 & 10.2 & 13.7 \\
\hline Current smokers, $\%$ & 20.5 & 20.2 & 20.4 & 20.2 & 20.2 & 20.4 & 20.3 & 20.3 \\
\hline $\begin{array}{l}\text { High alcohol consumption ( }>12 \mathrm{~g} \text { for } \\
\text { women, }>24 \mathrm{~g} \text { for men) }(\%)\end{array}$ & 32.9 & 22.1 & 27.1 & 27.9 & 27.1 & 27.9 & 29.1 & 25.8 \\
\hline Prevalent hypertension $(\%)$ & 47.2 & 44.6 & 44.1 & 47.7 & 41.8 & 50.3 & 47.1 & 44.7 \\
\hline Anti-hypertensive medication (\%) & 16.4 & 16.1 & 16.4 & 16.1 & 13.4 & 19.3 & 16.6 & 15.9 \\
\hline Lipid-lowering medication (\%) & 4.0 & 3.4 & 3.0 & 4.5 & 3.1 & 4.5 & 3.4 & 4.1 \\
\hline Mediterranean score ${ }^{\mathrm{b}}$ & $9.1(2.7)$ & $8.9(2.7)$ & $8.8(2.7)$ & $9.2(2.7)$ & $8.9(2.7)$ & $9.1(2.7)$ & $9.0(2.7)$ & $9.0(2.8)$ \\
\hline
\end{tabular}

Subcohort number for CVD outcome. Different number in subcohort participants due to outcome specific exclusions. Data are expressed as medians (IQR) ${ }^{\mathrm{a}}$ or means (SD) ${ }^{\mathbf{b}}$ for continuous variables and $\%$ for categorical variables

$B M I$ body mass index

model, the adjustment for $\mathrm{Cu}$ and I attenuated the relationship between the pattern and the risk of T2D (HR per SD, 95\% CI 0.95, 0.78-1.17 and 1.06, 0.90-1.24, respectively), whereas the adjustment for Se strengthened the magnitude of the association (HR per SD, 95\% CI 1.42, 1.13-1.78) (Table 3).

\section{TEs and risk of colorectal cancer}

In the spline regression analysis, the shapes of all observed associations were linear (Supplementary Fig. 4).

After adjustments for age, sex, education and established risk factors, higher concentrations of SELENOP and 
Table 2 Age and sex-adjusted Spearman correlations between TE and metabolic biomarker concentrations, EPIC-Potsdam, imputed sample, $n=3834$

\begin{tabular}{|c|c|c|c|c|c|c|c|c|c|c|c|}
\hline & $\mathrm{Mn}$ & $\mathrm{Fe}$ & $\mathrm{Cu}$ & $\mathrm{Zn}$ & I & $\mathrm{Se}$ & SELENOP & Free-Zn & $\mathrm{HbA1c}$ & HDL-C & HsCRP \\
\hline $\mathrm{Mn}$ & 1 & & & & & & & & & & \\
\hline $\mathrm{Fe}$ & 0.16 & 1 & & & & & & & & & \\
\hline $\mathrm{Cu}$ & 0.06 & 0.06 & 1 & & & & & & & & \\
\hline $\mathrm{Zn}$ & 0.04 & 0.25 & 0.12 & 1 & & & & & & & \\
\hline I & 0.04 & 0.10 & 0.43 & 0.17 & 1 & & & & & & \\
\hline $\mathrm{Se}$ & -0.06 & 0.08 & 0.20 & 0.26 & 0.27 & 1 & & & & & \\
\hline SELENOP & -0.01 & 0.01 & 0.06 & 0.11 & 0.06 & 0.45 & 1 & & & & \\
\hline Free-Zn & -0.01 & 0.06 & -0.03 & 0.33 & 0.01 & 0.03 & -0.03 & 1 & & & \\
\hline HbA1c & 0.11 & -0.06 & 0.07 & 0.05 & 0.02 & 0.03 & 0.14 & -0.01 & 1 & & \\
\hline HDL-C & 0.02 & 0.03 & 0.03 & -0.04 & -0.04 & 0.00 & -0.04 & 0.03 & -0.16 & 1 & \\
\hline HsCRP & 0.07 & -0.11 & 0.43 & -0.03 & 0.18 & 0.01 & 0.03 & -0.07 & 0.21 & -0.13 & 1 \\
\hline
\end{tabular}

$M n$ manganese, $\mathrm{Fe}$ iron, $\mathrm{Cu}$ copper, $\mathrm{Zn}$ zinc, $\mathrm{I}$ iodine, $\mathrm{Se}$ selenium, $S E L E N O P$ selenoprotein $\mathrm{P}, F r e e ~ Z n$ free zinc, $H D L-C$ high-density lipoprotein cholesterol, $H b A l c$ glycated hemoglobin, $H s C R P$ high-sensitivity $\mathrm{C}$-reactive protein

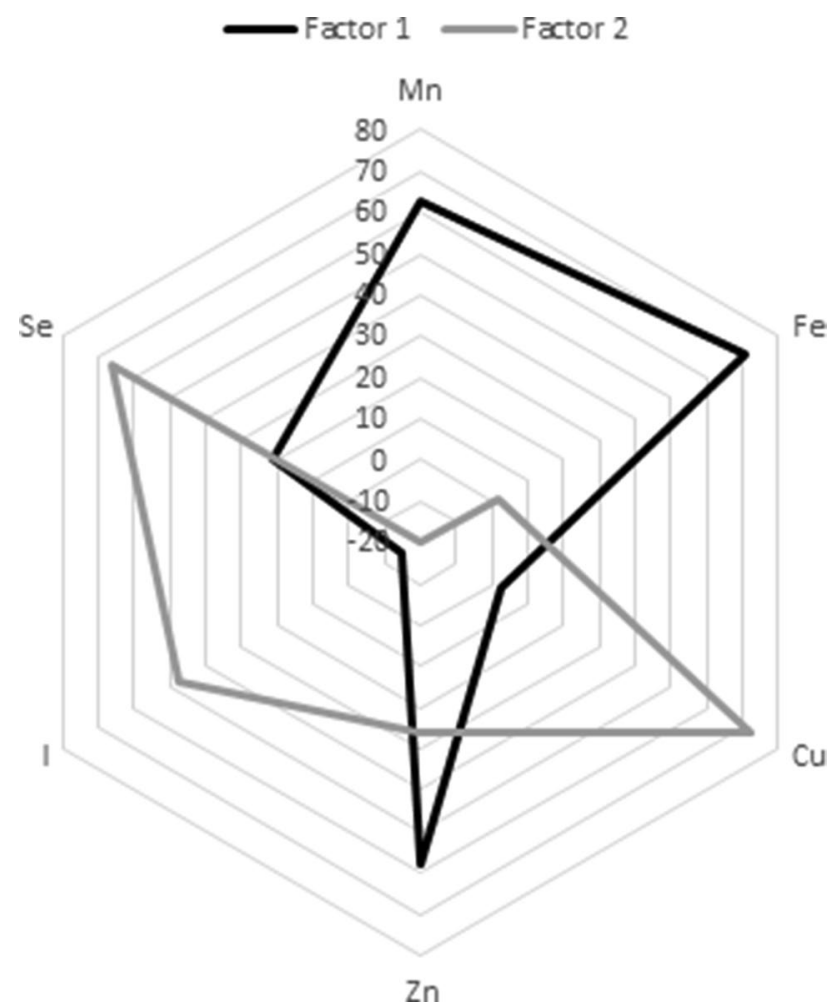

Fig. 1 Factor loadings after varimax rotation of the two PCA-derived factors based on TE concentrations at baseline, EPIC-Potsdam, imputed sample, $n=3834$. $M n$ manganese, $\mathrm{Fe}$ iron, $\mathrm{Cu}$ copper, $\mathrm{Zn}$ zinc, $I$ iodine, $S e$ selenium

Se-to-Cu ratio were associated with a lower risk of developing CRC (HR per SD, 95\% CI 0.80, 0.71-0.90 and 0.77, 0.65-0.92, respectively), while Free $\mathrm{Zn}$ was observed to associate with borderline significance with increased risk of CRC (HR per SD, 95\% CI 1.17, 1.00-1.38) (Fig. 2). In the final model, in which further adjustment was made for the respective other main TEs ( $\mathrm{Mn}, \mathrm{Fe}, \mathrm{Cu}, \mathrm{Zn}, \mathrm{I}$ and $\mathrm{Se}$ ), Free $\mathrm{Zn}$ lost statistical significance (HR per SD, 95\% CI $1.16,0.97-1.38$ ) and the association between SELENOP was similar to that of Se, with higher concentrations being associated with a lower risk of CRC (HR per SD, 95\% CI 0.81, 0.72-0.93 for SELENOP and 0.82, 0.69-0.98 for Se). Higher $\mathrm{Cu}$ concentrations, however, were associated with a higher risk of developing CRC (HR per SD, 95\% CI 1.29, 1.05-1.59) and $\mathrm{Zn}$ concentrations were associated with borderline significance (HR per SD, 95\% CI 1.14, 1.00-1.30). No associations were observed for the other TEs or the $\mathrm{Cu}$ to-Zn ratio (Supplementary Table 3).

No significant associations were observed between the TE patterns and the risk of developing CRC (Table 3).

In the sensitivity analysis, overall the associations were similar to those reported for all endpoints (data not shown).

\section{Discussion}

We found that selected TE concentrations were associated with incidence of all three outcomes (T2D, CVD or CRC). Most of the observed associations were linear and independent of age, sex, education, adiposity, lifestyle factors or the other TEs. We furthermore identified two major TE patterns that might help understanding the interplay of TEs: $\mathrm{Mn}-\mathrm{Fe}-\mathrm{Zn}$ and $\mathrm{Cu}-\mathrm{I}-\mathrm{Se}$. We observed a positive association between both patterns and the risk of developing T2D. The positive association of pattern 1 with T2D is consistent with the associations observed for individual component TEs (Mn and $\mathrm{Zn}$ ), while the associations of pattern 2 were largely explainable by $\mathrm{Se}$. In contrast, only the $\mathrm{Cu}-\mathrm{I}-\mathrm{Se}$ pattern was associated with the risk of developing CVD and none with 


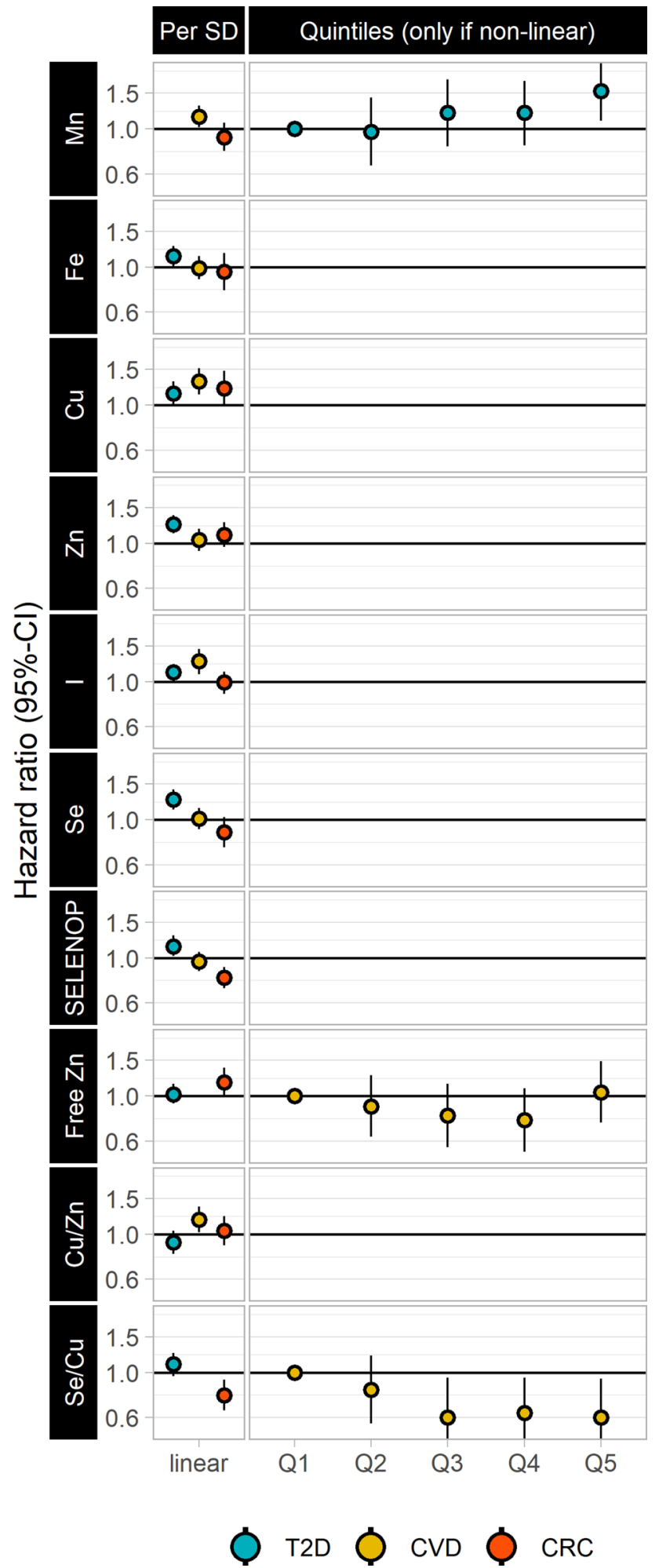

Fig. 2 Multivariable-adjusted hazard ratios for T2D, CVD or CRC according to TE concentration, EPIC-Potsdam. Model adjusted for age, sex, educational attainment, BMI, waist circumference, smoking status, physical activity, alcohol intake, vitamin and mineral preparations, prevalent hypertension, anti-hypertensive medication, lipid-lowering medication, and Mediterranean score. $M n$ manganese, $\mathrm{Fe}$ iron, $\mathrm{Cu}$ copper, $\mathrm{Zn}$ zinc, $I$ iodine, Se selenium, SELENOP selenoprotein $\mathrm{P}$, Free $Z n$ free zinc, $\mathrm{Cu} / \mathrm{Zn}$ copper-to-zinc ratio, $\mathrm{Se} / \mathrm{Cu}$ selenium-to-copper ratio
CRC. This likely reflects a dilution of association for some individual components by the lack of associations of other TEs or even contrasting associations among component TEs ( $\mathrm{Cu}$ and $\mathrm{Se}$ for $\mathrm{CRC})$.

Mn deficiency is uncommon given the variety of Mn-containing dietary sources. However, excessive and prolonged Mn exposure has been linked to neurological disorders [33, 34], while studies assessing other chronic diseases seem to be missing. Interestingly, our study suggests the existence of a J-shaped association of serum Mn levels and T2D, with high concentrations being associated with increased risk. Mn has furthermore been implicated in cancer prevention given the role of MnSOD in oncogenic activity and metabolic shifts during early tumorigenesis [35]. A role of Mn in age-related diseases is furthermore supported by genetic studies which have linked polymorphisms in MnSOD to various health outcomes, although not consistently [36]. Still, inconsistency across studies might partly be explainable by interaction with environmental factors like dietary Mn or antioxidant intake. For example, the common MnSOD Val16Ala polymorphism modified the association between an antioxidant-rich Mediterranean diet and breast cancer risk [37]. Still, in our study, we found no association between Mn concentrations and CRC risk.

Likewise, we observed an association between higher $\mathrm{Zn}$ concentrations and the risk of developing T2D. Zn is implicated in synthesis, storage, and secretion of insulin, as well as being a signaling molecule after insulin secretion [38]. $\mathrm{Zn}$ is transported to cells bound to proteins, predominantly albumin, a2-macroglobulin, and transferrin, but only free $\mathrm{Zn}$ ions are biologically active [39]. However, Zn concentrations in biological material have not been consistently related to diabetes risk [40, 41]. In two short-term interventions with $\mathrm{Zn}$ supplementation, no effect on HOMA-IR was detectable, nor do RCTs suggest effects on lipid biomarkers related to the metabolic syndrome [42]. Two prospective cohort studies on $\mathrm{Zn}$ biomarkers do not support a relationship to coronary heart disease [43] — we similarly did not observe an association for CVD, while a borderline association was found for CRC.

Higher $\mathrm{Cu}$ concentrations were associated to the risk of developing CVD and CRC. Similar to Zn, the serum concentrations of $\mathrm{Cu}$ are strictly regulated by feedback mechanisms that maintain its concentration within certain ranges independent of acute changes in nutritional intake. We found that high $\mathrm{Cu}$-to-Zn ratio was associated with an increased CVD risk. Similarly, high serum $\mathrm{Cu}$-to- $\mathrm{Zn}$ ratio was associated with cardiovascular and all-cause mortality among middleaged men in the Paris Prospective Study 2 [44], and among elderly subjects in the ilSIRENTE Study [45], as well as to CRC in the EPIC cohort study [46]. In addition, a synergistic effect between the pro-oxidative effects of elevated $\mathrm{Cu}$ in the presence of low status of Se, the essential component of 
Table 3 Results of the stepwise approach: hazard ratios (95\% CIs) for T2D, CVD or CRC according to TE patterns adding one by one the TE to model 2, EPIC-Potsdam, imputed sample

\begin{tabular}{|c|c|c|c|c|c|c|c|c|c|}
\hline & $\begin{array}{l}\text { No. of } \\
\text { cases/ } \\
\text { non-cases }\end{array}$ & Model 1 & Model 2 & $\begin{array}{l}\text { Model } 2 \\
+ \text { Mn }\end{array}$ & $\begin{array}{l}\text { Model } 2 \\
+\mathrm{Fe}\end{array}$ & $\begin{array}{l}\text { Model } 2 \\
+\mathrm{Cu}\end{array}$ & $\begin{array}{l}\text { Model } 2 \\
+\mathrm{Zn}\end{array}$ & $\begin{array}{l}\text { Model } 2 \\
+\mathrm{I}\end{array}$ & $\begin{array}{l}\text { Model } 2 \\
+ \text { Se }\end{array}$ \\
\hline \multicolumn{10}{|c|}{ Type 2 diabetes } \\
\hline Factor 1 & $705 / 2036$ & $\begin{array}{l}1.09 \\
(1.01-1.17)\end{array}$ & $\begin{array}{l}1.19 \\
(1.09-1.30)\end{array}$ & $\begin{array}{l}1.15 \\
(1.04-1.27)\end{array}$ & $\begin{array}{l}1.19 \\
(1.07-1.33)\end{array}$ & $\begin{array}{l}1.19 \\
(1.08-1.30)\end{array}$ & $\begin{array}{l}1.11 \\
(1.00-1.24)\end{array}$ & $\begin{array}{l}1.21 \\
(1.11-1.32)\end{array}$ & $\begin{array}{l}1.17 \\
(1.06-1.28)\end{array}$ \\
\hline \multicolumn{10}{|l|}{ Factor 2} \\
\hline Quintile 1 & $158 / 415$ & 1 (reference) & 1 (reference) & 1 (reference) & 1 (reference) & 1 (reference) & 1 (reference) & 1 (reference) & 1 (reference) \\
\hline Quintile 2 & $119 / 402$ & $\begin{array}{l}0.94 \\
(0.68-1.29)\end{array}$ & $\begin{array}{l}0.92 \\
(0.63-1.34)\end{array}$ & $\begin{array}{l}0.94 \\
(0.65-1.37)\end{array}$ & $\begin{array}{l}0.91 \\
(0.62-1.32)\end{array}$ & $\begin{array}{l}0.93 \\
(0.63-1.37)\end{array}$ & $\begin{array}{l}0.86 \\
(0.59-1.26)\end{array}$ & $\begin{array}{l}0.89 \\
(0.61-1.31)\end{array}$ & $\begin{array}{l}0.77 \\
(0.51-1.16)\end{array}$ \\
\hline Quintile 3 & $150 / 416$ & $\begin{array}{l}1.02 \\
(0.76-1.36)\end{array}$ & $\begin{array}{l}0.92 \\
(0.65-1.30)\end{array}$ & $\begin{array}{l}0.98 \\
(0.69-1.39)\end{array}$ & $\begin{array}{l}0.92 \\
(0.65-1.31)\end{array}$ & $\begin{array}{l}0.93 \\
(0.65-1.34)\end{array}$ & $\begin{array}{l}0.85 \\
(0.59-1.21)\end{array}$ & $\begin{array}{l}0.89 \\
(0.63-1.26)\end{array}$ & $\begin{array}{l}0.70 \\
(0.46-1.07)\end{array}$ \\
\hline Quintile 4 & $137 / 384$ & $\begin{array}{l}1.24 \\
(0.92-1.67)\end{array}$ & $\begin{array}{l}1.21 \\
(0.85-1.72)\end{array}$ & $\begin{array}{l}1.27 \\
(0.89-1.81)\end{array}$ & $\begin{array}{l}1.22 \\
(0.86-1.74)\end{array}$ & $\begin{array}{l}1.25 \\
(0.84-1.84)\end{array}$ & $\begin{array}{l}1.08 \\
(0.75-1.56)\end{array}$ & $\begin{array}{l}1.45 \\
(0.80-1.64)\end{array}$ & $\begin{array}{l}0.84 \\
(0.51-1.38)\end{array}$ \\
\hline Quintile 5 & $141 / 419$ & $\begin{array}{l}1.66 \\
(1.22-2.27)\end{array}$ & $\begin{array}{l}1.76 \\
(1.21-2.56)\end{array}$ & $\begin{array}{l}1.88 \\
(1.29-2.75)\end{array}$ & $\begin{array}{l}1.74 \\
(1.20-2.54)\end{array}$ & $\begin{array}{l}1.86 \\
(1.16-2.98)\end{array}$ & $\begin{array}{l}1.47 \\
(0.98-2.18)\end{array}$ & $\begin{array}{l}1.59 \\
(1.07-2.38)\end{array}$ & $\begin{array}{l}1.02 \\
(0.54-1.94)\end{array}$ \\
\hline \multicolumn{10}{|c|}{ Cardiovascular disease } \\
\hline Factor 1 & $414 / 2050$ & $\begin{array}{l}1.03 \\
(0.93-1.14)\end{array}$ & $\begin{array}{l}1.04 \\
(0.93-1.16)\end{array}$ & $\begin{array}{l}0.96 \\
(0.84-1.09)\end{array}$ & $\begin{array}{l}1.07 \\
(0.95-1.20)\end{array}$ & $\begin{array}{l}1.02 \\
(0.92-1.14)\end{array}$ & $\begin{array}{l}1.02 \\
(0.90-1.16)\end{array}$ & $\begin{array}{l}1.01 \\
(0.90-1.14)\end{array}$ & $\begin{array}{l}1.03 \\
(0.93-1.15)\end{array}$ \\
\hline Factor 2 & $414 / 2050$ & $\begin{array}{l}1.20 \\
(1.05-1.37)\end{array}$ & $\begin{array}{l}1.17 \\
(1.02-1.35)\end{array}$ & $\begin{array}{l}1.21 \\
(1.06-1.38)\end{array}$ & $\begin{array}{l}1.17 \\
(1.02-1.35)\end{array}$ & $\begin{array}{l}0.95 \\
(0.78-1.17)\end{array}$ & $\begin{array}{l}1.18 \\
(1.02-1.36)\end{array}$ & $\begin{array}{l}1.06 \\
(0.90-1.24)\end{array}$ & $\begin{array}{l}1.42 \\
(1.13-1.78)\end{array}$ \\
\hline \multicolumn{10}{|c|}{ Colorectal cancer } \\
\hline Factor 1 & $219 / 2090$ & $\begin{array}{l}1.00 \\
(0.88-1.37)\end{array}$ & $\begin{array}{l}0.99 \\
(0.86-1.14)\end{array}$ & $\begin{array}{l}1.03 \\
(0.88-1.20)\end{array}$ & $\begin{array}{l}1.03 \\
(0.90-1.19)\end{array}$ & $\begin{array}{l}0.99 \\
(0.86-1.14)\end{array}$ & $\begin{array}{l}0.92 \\
(0.77-1.10)\end{array}$ & $\begin{array}{l}0.99 \\
(0.85-1.15)\end{array}$ & $\begin{array}{l}1.00 \\
(0.88-1.15)\end{array}$ \\
\hline Factor 2 & $219 / 2090$ & $\begin{array}{l}1.00 \\
(0.90-1.11)\end{array}$ & $\begin{array}{l}0.99 \\
(0.89-1.11)\end{array}$ & $\begin{array}{l}0.98 \\
(0.87-1.11)\end{array}$ & $\begin{array}{l}0.99 \\
(0.89-1.11)\end{array}$ & $\begin{array}{l}0.84 \\
(0.67-1.05)\end{array}$ & $\begin{array}{l}0.97 \\
(0.85-1.10)\end{array}$ & $\begin{array}{l}1.01 \\
(0.84-1.21)\end{array}$ & $\begin{array}{l}1.05 \\
(1.96-1.15)\end{array}$ \\
\hline
\end{tabular}

Model 1: adjusted for age and sex, Model 2: adjusted for age, sex, educational attainment, BMI, waist circumference, smoking status, physical activity, alcohol intake, vitamin and mineral preparations, prevalent hypertension, anti-hypertensive medication, lipid-lowering medication, and Mediterranean score

antioxidant selenoproteins, has been suggested [47]. Accordingly, we observed an inverse association between Se-to- $\mathrm{Cu}$ ratio and the risk of developing CVD as well as CRC.

Interestingly, our results indicate opposite associations of Se and T2D versus CRC. The latter was also observed for SELENOP, a functional biomarker of Se status. Prospective studies have generally shown some benefit of higher Se status on the risk of various cancers [2, 3]. However, findings from intervention trials have been mixed [4], which probably emphasizes that supplementation will confer benefit only if intake is inadequate. A recent systematic analysis, including 13 observational studies with more than 30,000 subjects, and 3 RCTs involving more than 20,000 participants, does support a positive association between Se and odds for T2D, but indicates no increased risk upon supplemental Se intake, i.e., divergent results between observational studies and RCTs [48]. Interestingly, we found a positive association of Se with T2D in our study, but a lack of association between SELENOP and T2D after adjustment for other TEs. This finding may indicate that the underlying etiopathogenic mechanisms are more complex than anticipated, and larger and more refined studies are needed for clarifying the association, especially in view of the different subgroups of patients [49]. Regarding Se status and CVD risk, neither Se nor SELENOP showed a significant association, in contrast to the strong associations observed for Se-deficient subjects and CVD in the Malmö Preventive Project published recently [50]. Nevertheless, the Se-to-Cu ratio emerged as a most sensitive parameter for CVD risk, supporting our hypothesis on the importance of TE patterns as highly informative disease-related biomarkers.

We found that high I concentrations were associated with an increased risk of developing T2D, similarly to the E3N-EPIC cohort [51]. High intakes of I may accelerate the development of thyroid disorders, such as hypothyroidism or hyperthyroidism, and have been described to increase the incidence of autoimmune thyroiditis and thyroid cancer risk in China [52]. Again, it will be highly important to conduct future studies on the relation of I with thyroid disease risk in relation to other TEs, especially $\mathrm{Fe}$ and $\mathrm{Se}$, and deduce the predictive or diagnostic relevance of composite TE biomarkers [53]. 
Iron is the most abundant trace metal in the human organism. Although both low and high levels have been associated with health outcomes [54, 55], we did not observe a significant association between total Fe concentrations with any of our endpoints. Nevertheless, we have previously reported from the EPIC-Potsdam study that high serum ferritin levels were associated with higher risk of T2D, while no significant association was observed for soluble transferrin receptor concentrations [56]. This indicates that total serum Fe is a different and not-linearly overlapping marker of Fe status as compared to ferritin concentrations.

Our study was conducted in a well-characterized study population embedded into the EPIC-Potsdam cohort. The novelty of considering multiple essential TEs and TE ratios as composite biomarkers with validated methods, and assessing their relation with three different outcomes that include some of the most common diseases in terms of incidence and mortality worldwide is a major strength of this study. TEs were measured before disease onset, thereby reducing the possibility that biomarker levels changed as a result of the outcome. Furthermore, follow-up proportions exceeded 90\%; and all self-reports on incident T2D, CVD and CRC cases were verified through medical records, treating physicians, or death certificates. Nevertheless, the study has some limitations. We relied on a single baseline blood sample and random measurement errors may have attenuated true relations of TEs and endpoints. The samples were stored until time of analysis. Total elemental concentrations are generally very stable, especially in frozen samples and at the $\mathrm{pH}$ of serum $(\sim 7.4)$. Even if interconversion of elemental species occurred, this would not change the total amount of the elements in solution, unless volatile or insoluble species were created, which is unlikely under these storage conditions [57]. Due to missing data, some values were imputed. Nevertheless, in the sensitivity analyses restricted to individuals with available data, the trends in the associations between TE concentrations and different endpoints were comparable to those from the imputed dataset (data not shown). Finally, given the observational nature of this study, causality cannot be proven and we can only speculate on potential pathways that link TE concentrations to chronic disease development.

In conclusion, our study illustrates several strong associations between TEs and T2D, CVD or CRC. Noteworthy, most associations were independent of other TEs. Positive associations were found between $\mathrm{Mn}, \mathrm{I}, \mathrm{Zn}$ and Se with T2D incidence, $\mathrm{Mn}, \mathrm{Cu}$ and $\mathrm{Cu}$-to- $\mathrm{Zn}$ ratio with $\mathrm{CVD}$ incidence, as well as $\mathrm{Zn}$ and $\mathrm{Cu}$ with $\mathrm{CRC}$ incidence. Inverse associations were observed for Se and $\mathrm{CRC}$, contrasting the positive association observed for T2D. SELENOP and the Se-to-Cu ratio were inversely associated to $\mathrm{CRC}$, the latter was also observed for CVD. The contrasting associations found for Se might point towards differential disease-related pathways, and the identification of the highly sensitive Se-to- $\mathrm{Cu}$ ratio as novel parameter for CVD risk supports the concept of TE patterns as meaningful biomarkers of human disease.

Supplementary Information The online version contains supplementary material available at https://doi.org/10.1007/s00394-021-02494-3.

Acknowledgements We thank the Human Study Centre (HSC) of the German Institute of Human Nutrition Potsdam-Rehbruecke for the collection, the data hub for the processing, the participants for the provision of the data. We would also like to thank Manuela Bergman, head of the HSC, for the contribution to the study design and data generation, and Ellen Kohlsdorf for data handling and technical assistance, and Gabrielle Pohl for the sample preparation.

Author contributions The authors' responsibilities were as follows: MBS was responsible for the design of the study; TS, APK, HH, LS and MBS were responsible for the general concept of the research; $\mathrm{JFK}, \mathrm{JH}$, and WA contributed to the data collection; MC, OK and FE contributed to the data analysis; MC and MBS were responsible for writing the manuscript; all authors contributed to the interpretation of data and revision of the manuscript; $\mathrm{MC}$ had primary responsibility for the final content of the manuscript.

Funding Open Access funding enabled and organized by Projekt DEAL. This work was funded by TraceAge-DFG Research Unit on Interactions of essential trace elements in healthy and diseased elderly, Potsdam-Berlin-Jena (FOR 2558/1). The EPIC-Potsdam recruitment phase study was supported by the Federal Ministry of Science, Germany (Grant 01 EA 9401) and the European Union (Grant SOC 9520140805 F02). Follow-up of EPIC-Potsdam was supported by the German Cancer Aid (Grant 70-2488-Ha I), the European Community (Grant SOC 9820076905 F02). The funders had no role in study design, data collection and analysis, decision to publish or preparation of the manuscript.

\section{Compliance with ethical standards}

Conflict of interest The authors declare that they have no conflict of interest.

Ethics approval The study was approved by the ethics committee of the Medical Society of the State of Brandenburg.

Consent to participate Written informed consent was obtained from all study participants a priori.

Consent for publication All authors read and approved the final manuscript.

Data sharing The datasets analyzed during the current study are not publicly available due to data protection regulations. In accordance with German Federal and State data protection regulations, epidemiological data analyses of EPIC-Potsdam may be initiated upon an informal inquiry addressed to the secretariat of the Human Study Center (Office.HSZ@dife.de). Each request will then have to pass a formal process of application and review by the respective PI and a scientific board.

Open Access This article is licensed under a Creative Commons Attribution 4.0 International License, which permits use, sharing, adaptation, distribution and reproduction in any medium or format, as long as you give appropriate credit to the original author(s) and the source, 
provide a link to the Creative Commons licence, and indicate if changes were made. The images or other third party material in this article are included in the article's Creative Commons licence, unless indicated otherwise in a credit line to the material. If material is not included in the article's Creative Commons licence and your intended use is not permitted by statutory regulation or exceeds the permitted use, you will need to obtain permission directly from the copyright holder. To view a copy of this licence, visit http://creativecommons.org/licenses/by/4.0/.

\section{References}

1. Bornhorst J, Kipp AP, Haase H, Meyer S, Schwerdtle T (2018) The crux of inept biomarkers for risks and benefits of trace elements. TrAC Trends Anal Chem 104:183-190

2. Hurst R, Hooper L, Norat T, Lau R, Aune D, Greenwood DC, Vieira R, Collings R, Harvey LJ, Sterne JA (2012) Selenium and prostate cancer: systematic review and meta-analysis. Am J Clin Nutr 96(1):111-122

3. Hughes DJ, Fedirko V, Jenab M, Schomburg L, Méplan C, Freisling H, Bueno-de-Mesquita HB, Hybsier S, Becker NP, Czuban M (2015) Selenium status is associated with colorectal cancer risk in the European prospective investigation of cancer and nutrition cohort. Int J Cancer 136(5):1149-1161

4. Cai X, Wang C, Yu W, Fan W, Wang S, Shen N, Wu P, Li X, Wang F (2016) Selenium exposure and cancer risk: an updated meta-analysis and meta-regression. Sci Rep 6:19213

5. Lee S-H, Jouihan HA, Cooksey RC, Jones D, Kim HJ, Winge DR, McClain DA (2013) Manganese supplementation protects against diet-induced diabetes in wild type mice by enhancing insulin secretion. Endocrinology 154(3):1029-1038

6. Shan Z, Chen S, Sun T, Luo C, Guo Y, Yu X, Yang W, Hu FB, Liu L (2016) U-shaped association between plasma manganese levels and type 2 diabetes. Environ Health Perspect 124(12):1876-1881

7. Caspersen IH, Thomsen C, Haug LS, Knutsen HK, Brantsæter AL, Papadopoulou E, Erlund I, Lundh T, Alexander J, Meltzer HM (2019) Patterns and dietary determinants of essential and toxic elements in blood measured in mid-pregnancy: the Norwegian Environmental Biobank. Sci Total Environ 671:299-308

8. von Stackelberg K, Guzy E, Chu T, Henn BC (2015) Exposure to mixtures of metals and neurodevelopmental outcomes: a multidisciplinary review using an adverse outcome pathway framework. Risk Anal 35(6):971-1016

9. Sanders AP, Henn BC, Wright RO (2015) Perinatal and childhood exposure to cadmium, manganese, and metal mixtures and effects on cognition and behavior: a review of recent literature. Curr Environ Health Rep 2(3):284-294

10. Stohs SJ, Bagchi D (1995) Oxidative mechanisms in the toxicity of metal ions. Free Radical Biol Med 18(2):321-336

11. Malavolta M, Piacenza F, Basso A, Giacconi R, Costarelli L, Mocchegiani E (2015) Serum copper to zinc ratio: relationship with aging and health status. Mech Ageing Dev 151:93-100

12. Boeing H, Wahrendorf J, Becker N (1999) EPIC-Germany-a source for studies into diet and risk of chronic diseases. Ann Nutr Metab 43(4): 195-204

13. Boeing H, Korfmann A, Bergmann MM (1999) Recruitment procedures of EPIC-Germany. European Investigation into Cancer and Nutrition. Ann Nutr Metab 43(4):205-215

14. Kroke A, Klipstein-Grobusch K, Voss S, Möseneder J, Thielecke F, Noack R, Boeing H (1999) Validation of a selfadministered food-frequency questionnaire administered in the European Prospective Investigation into Cancer and Nutrition
(EPIC) Study: comparison of energy, protein, and macronutrient intakes estimated with the doubly labeled water, urinary nitrogen, and repeated 24-h dietary recall methods. Am J Clin Nutr 70(4):439-447

15. Schienkiewitz A, Schulze MB, Hoffmann K, Kroke A, Boeing H (2006) Body mass index history and risk of type 2 diabetes: results from the European Prospective Investigation into Cancer and Nutrition (EPIC)—Potsdam Study. Am J Clin Nutr 84(2):427-433

16. Prentice RL (1986) A case-cohort design for epidemiologic cohort studies and disease prevention trials. Biometrika 73(1):1-11

17. Kopp JF, Müller SM, Pohl G, Lossow K, Kipp AP, Schwerdtle T (2019) A quick and simple method for the determination of six trace elements in mammalian serum samples using ICP-MS/MS. J Trace Elem Med Biol 54:221-225

18. Baudry J, Kopp JF, Boeing H, Kipp AP, Schwerdtle T, Schulze MB (2019) Changes of trace element status during aging: results of the EPIC-Potsdam cohort study. Eur J Nutr 59:1-14

19. Hybsier S, Schulz T, Wu Z, Demuth I, Minich WB, Renko K, Rijntjes E, Köhrle J, Strasburger CJ, Steinhagen-Thiessen E (2017) Sex-specific and inter-individual differences in biomarkers of selenium status identified by a calibrated ELISA for selenoprotein P. Redox Biol 11:403-414

20. Saito Y, Misu H, Takayama H, Takashima S-i, Usui S, Takamura M, Kaneko S, Takamura T, Noguchi N (2018) Comparison of human selenoprotein $\mathrm{P}$ determinants in serum between our original methods and commercially available kits. Biol Pharm Bull 41(5):828-832

21. Alker W, Schwerdtle T, Schomburg L, Haase H (2019) A Zinpyr1-based fluorimetric microassay for free zinc in human serum. Int J Mol Sci 20(16):4006

22. Enzenbach C, Kröger J, Zietemann V, Jansen EH, Fritsche A, Döring F, Boeing H, Schulze MB (2011) Erythrocyte membrane phospholipid polyunsaturated fatty acids are related to plasma $\mathrm{C}$-reactive protein and adiponectin in middle-aged German women and men. Eur J Nutr 50(8):625-636

23. Jacobs S, Kröger J, Floegel A, Boeing H, Drogan D, Pischon T, Fritsche A, Prehn C, Adamski J, Isermann B (2014) Evaluation of various biomarkers as potential mediators of the association between coffee consumption and incident type 2 diabetes in the EPIC-Potsdam Study. Am J Clin Nutr 100(3):891-900

24. Weikert C, Berger K, Heidemann C, Bergmann MM, Hoffmann K, Klipstein-Grobusch K, Boeing H (2007) Joint effects of risk factors for stroke and transient ischemic attack in a German population. J Neurol 254(3):315-321

25. Tunstall-Pedoe H, Kuulasmaa K, Amouyel P, Arveiler D, Rajakangas A-M, Pajak A (1994) Myocardial infarction and coronary deaths in the World Health Organization MONICA. Project Registration procedures, event rates, and case-fatality rates in 38 populations from 21 countries in four continents. Circulation 90(1):583-612

26. Organization WH (2004) International statistical classification of diseases and related health problems: instruction manual, vol 2. World Health Organization, Geneva

27. Kroke A, Bergmann M, Lotze G, Jeckel A, Klipstein-Grobusch $\mathrm{K}$, Boeing H (1999) Measures of quality control in the German component of the EPIC study. Ann Nutr Metab 43(4):216-224

28. Bohlscheid-Thomas S, Hoting I, Boeing H, Wahrendorf J (1997) Reproducibility and relative validity of food group intake in a food frequency questionnaire developed for the German part of the EPIC project. European Prospective Investigation into Cancer and Nutrition. Int J Epidemiol 26(suppl_1):S59

29. Galbete C, Kröger J, Jannasch F, Iqbal K, Schwingshackl L, Schwedhelm C, Weikert C, Boeing H, Schulze MB (2018) Nordic diet, Mediterranean diet, and the risk of chronic diseases: the EPIC-Potsdam study. BMC Med 16(1):99 
30. Van Buuren S (2007) Multiple imputation of discrete and continuous data by fully conditional specification. Stat Methods Med Res 16(3):219-242

31. Barlow WE, Ichikawa L, Rosner D, Izumi S (1999) Analysis of case-cohort designs. J Clin Epidemiol 52(12):1165-1172

32. Lin DY, Wei L-J (1989) The robust inference for the Cox proportional hazards model. J Am Stat Assoc 84(408):1074-1078

33. Racette BA (2014) Manganism in the 21st century: the Hanninen lecture. Neurotoxicology 45:201-207

34. Andruska KM, Racette BA (2015) Neuromythology of manganism. Curr Epidemiol Rep 2(2):143-148

35. Robbins D, Zhao Y (2014) Manganese superoxide dismutase in cancer prevention. Antioxid Redox Signal 20(10):1628-1645

36. Bresciani G, Cruz I, De Paz J, Cuevas M, González-Gallego J (2013) The MnSOD Ala16Val SNP: relevance to human diseases and interaction with environmental factors. Free Radic Res 47(10):781-792

37. Kakkoura MG, Demetriou CA, Loizidou MA, Loucaides G, Neophytou I, Malas S, Kyriacou K, Hadjisavvas A (2016) MnSOD and CAT polymorphisms modulate the effect of the Mediterranean diet on breast cancer risk among Greek-Cypriot women. Eur J Nutr 55(4): 1535-1544

38. Myers SA (2015) Zinc transporters and zinc signaling: new insights into their role in type 2 diabetes. Int $\mathrm{J}$ Endocrinol 2015:1-7

39. Vallee BL, Falchuk KH (1993) The biochemical basis of zinc physiology. Physiol Rev 73(1):79-118

40. Yary T, Virtanen JK, Ruusunen A, Tuomainen T-P, Voutilainen S (2016) Serum zinc and risk of type 2 diabetes incidence in men: the Kuopio Ischaemic Heart Disease Risk Factor Study. J Trace Elem Med Biol 33:120-124

41. Park JS, Xun P, Li J, Morris SJ, Jacobs DR, Liu K, He K (2016) Longitudinal association between toenail zinc levels and the incidence of diabetes among American young adults: the CARDIA Trace Element Study. Sci Rep 6:23155

42. El Dib R, Gameiro OL, Ogata MS, Módolo NS, Braz LG, Jorge EC, do Nascimento P Jr, Beletate V (2015) Zinc supplementation for the prevention of type 2 diabetes mellitus in adults with insulin resistance. Cochrane Database Syst Rev (5):CD005525

43. Hashemian M, Poustchi H, Mohammadi-Nasrabadi F, Hekmatdoost A (2015) Systematic review of zinc biochemical indicators and risk of coronary heart disease. ARYA Atherosclerosis 11(6):357-365

44. Leone N, Courbon D, Ducimetiere P, Zureik M (2006) Zinc, copper, and magnesium and risks for all-cause, cancer, and cardiovascular mortality. Epidemiology 17(3):308-314

45. Mocchegiani E, Malavolta M, Lattanzio F, Piacenza F, Basso A, Abbatecola AM, Russo A, Giovannini S, Capoluongo E, Bustacchini S (2012) Cu to Zn ratio, physical function, disability, and mortality risk in older elderly (ilSIRENTE study). Age 34(3):539-552

46. Stepien M, Jenab M, Freisling H, Becker N-P, Czuban M, Tjønneland A, Olsen A, Overvad K, Boutron-Ruault M-C, Mancini FR (2017) Pre-diagnostic copper and zinc biomarkers and colorectal cancer risk in the European Prospective Investigation into Cancer and Nutrition cohort. Carcinogenesis 38(7):699-707

47. Salonen JT, Salonen R, Korpela H, Suntioinen S, Tuomilehto J (1991) Serum copper and the risk of acute myocardial infarction: a prospective population study in men in eastern Finland. Am J Epidemiol 134(3):268-276

48. Kohler LN, Foote J, Kelley CP, Florea A, Shelly C, Chow H-H, Hsu P, Batai K, Ellis N, Saboda K (2018) Selenium and type 2 diabetes: systematic review. Nutrients 10(12):1924

49. Ahlqvist E, Storm P, Karajamaki A, Martinell M, Dorkhan M, Carlsson A, Vikman P, Prasad RB, Aly DM, Almgren P, Wessman Y, Shaat N, Spegel P, Mulder H, Lindholm E, Melander O, Hansson O, Malmqvist U, Lernmark A, Lahti K, Forsen T, Tuomi T, Rosengren AH, Groop L (2018) Novel subgroups of adultonset diabetes and their association with outcomes: a data-driven cluster analysis of six variables. Lancet Diabetes Endocrinol 6(5):361-369

50. Schomburg L, Orho-Melander M, Struck J, Bergmann A, Melander O (2019) Selenoprotein-P deficiency predicts cardiovascular disease and death. Nutrients 11(8):1852

51. Mancini FR, Rajaobelina K, Dow C, Habbal T, Affret A, Balkau B, Bonnet F, Boutron-Ruault M-C, Fagherazzi G (2019) High iodine dietary intake is associated with type 2 diabetes among women of the E3N-EPIC cohort study. Clin Nutr 38(4):1651-1656

52. Teng W, Shan Z, Teng X, Guan H, Li Y, Teng D, Jin Y, Yu X, Fan C, Chong W (2006) Effect of iodine intake on thyroid diseases in China. N Engl J Med 354(26):2783-2793

53. Rayman MP (2019) Multiple nutritional factors and thyroid disease, with particular reference to autoimmune thyroid disease. Proc Nutr Soc 78(1):34-44

54. Torti SV, Torti FM (2013) Iron and cancer: more ore to be mined. Nat Rev Cancer 13(5):342

55. Jiang R, Manson JE, Meigs JB, Ma J, Rifai N, Hu FB (2004) Body iron stores in relation to risk of type 2 diabetes in apparently healthy women. JAMA 291(6):711-717

56. Montonen J, Boeing H, Steffen A, Lehmann R, Fritsche A, Joost H-G, Schulze M, Pischon T (2012) Body iron stores and risk of type 2 diabetes: results from the European Prospective Investigation into Cancer and Nutrition (EPIC)-Potsdam study. Diabetologia 55(10):2613-2621

57. Cornelis R, Heinzow B, Herber R, Christensen JM, Poulsen O, Sabbioni E, Templeton D, Thomassen Y, Vahter M, Vesterberg O (1996) Sample collection guidelines for trace elements in blood and urine. J Trace Elem Med Biol 10(2):103-127 